\title{
Infected Schmorl's node: a case report
}

\author{
Hyeun Sung Kim*, Harshavardhan Dilip Raorane, Sagar Bhupendra Sharma, Pang Hung Wu and II-Tae Jang
}

\begin{abstract}
Background: Schmorls node (SN) are mostly asymptomatic and incidental findings on MRI. However, sometimes they present like acute onset low back pain or acute exacerbation of chronic back pain after minor trauma.

Case presentation: We present rare case of symptomatic infected SN in 67 years female patient presented with complains of low back pain radiating to right buttock. After initial conservative treatment failed subsequent imaging showed significant increase in size of lesion with focal signal changes in disc space gave suspicion of underlying secondary pathology. Patient operated for complete excision of lesion. Histopathological report was suggestive of pyogenic vertebral osteomyelitis. Patient improved well postoperatively.
\end{abstract}

Conclusion: Most of the time acute SN responds well to conservative treatment; however rapid deterioration of symptoms or persistent severe pain should give suspicion of underlying secondary pathology.

Keywords: Schmorl's node, Symptomatic, Infected, MRI

\section{Background}

Schmorl's node (SN) is herniation of intervertebral disc into vertebral body through end plate defect. They first described by Christian Schmorl in 1927. SN are mostly asymptomatic and incidental findings on MRI; however sometimes they present like acute onset low back pain or acute exacerbation of chronic back pain after minor trauma $[1,2]$. At that time they are called as acute SN. A number of theories have been proposed to explain the pathogenesis of $\mathrm{SN}$ which consist of developmental disease [3], degenerative disease [4], traumatic [5] or as part of autoimmune disorder [6]; still exact etiology of $\mathrm{SN}$ is unknown.

We present atypical presentation of acute symptomatic $\mathrm{SN}$ with infective pathology. There are no reports in the literature regarding the occurrence, imaging follow-up, treatment and outcome of symptomatic acute infective SN till date.

\footnotetext{
* Correspondence: neurospinekim@gmail.com Department of Neurosurgery, Nanoori Hospital Gangnam, 731, Eonju-ro, Gangnam-gu, Seoul 06048, Republic of Korea
}

\section{Case presentation \\ Case history}

Sixty-seven years female patient presented to our hospital with complains of low back pain radiating to right buttock since 1 month with visual analogue scale (VAS) score 7. There was no associated fever or significant trauma in recent past. She had no other medical or surgical history in the past. Clinically, there was no tenderness over lumbar spine. Patient was neurologically intact.

\section{Investigations}

A plain radiograph of lumbar spine was showing L4-5 narrowing of disc space with mild degenerative scoliosis. Dynamic plain radiograph does not show any features of instability. Computed tomography (CT) scan showed osteolytic bone lesion at inferior end plate of L3 vertebral body (Fig. 1). Initial magnetic resonance imagining (MRI) revealed an acute $\mathrm{SN}$ at lower end plate of L3 vertebral body without surrounding marrow signal changes (Fig. 2). A diagnosis of acute Schmorl's node L3 vertebral body was made. Initial MRI and imaging findings of infected SN were difficult to suspect infective pathology; hence managed conservatively. Repeat subsequent

(c) The Author(s). 2020 Open Access This article is licensed under a Creative Commons Attribution 4.0 International License, which permits use, sharing, adaptation, distribution and reproduction in any medium or format, as long as you give appropriate credit to the original author(s) and the source, provide a link to the Creative Commons licence, and indicate if changes were made. The images or other third party material in this article are included in the article's Creative Commons licence, unless indicated otherwise in a credit line to the material. If material is not included in the article's Creative Commons licence and your intended use is not permitted by statutory regulation or exceeds the permitted use, you will need to obtain permission directly from the copyright holder. To view a copy of this licence, visit http://creativecommons.org/licenses/by/4.0/ The Creative Commons Public Domain Dedication waiver (http://creativecommons.org/publicdomain/zero/1.0/) applies to the data made available in this article, unless otherwise stated in a credit line to the data. 


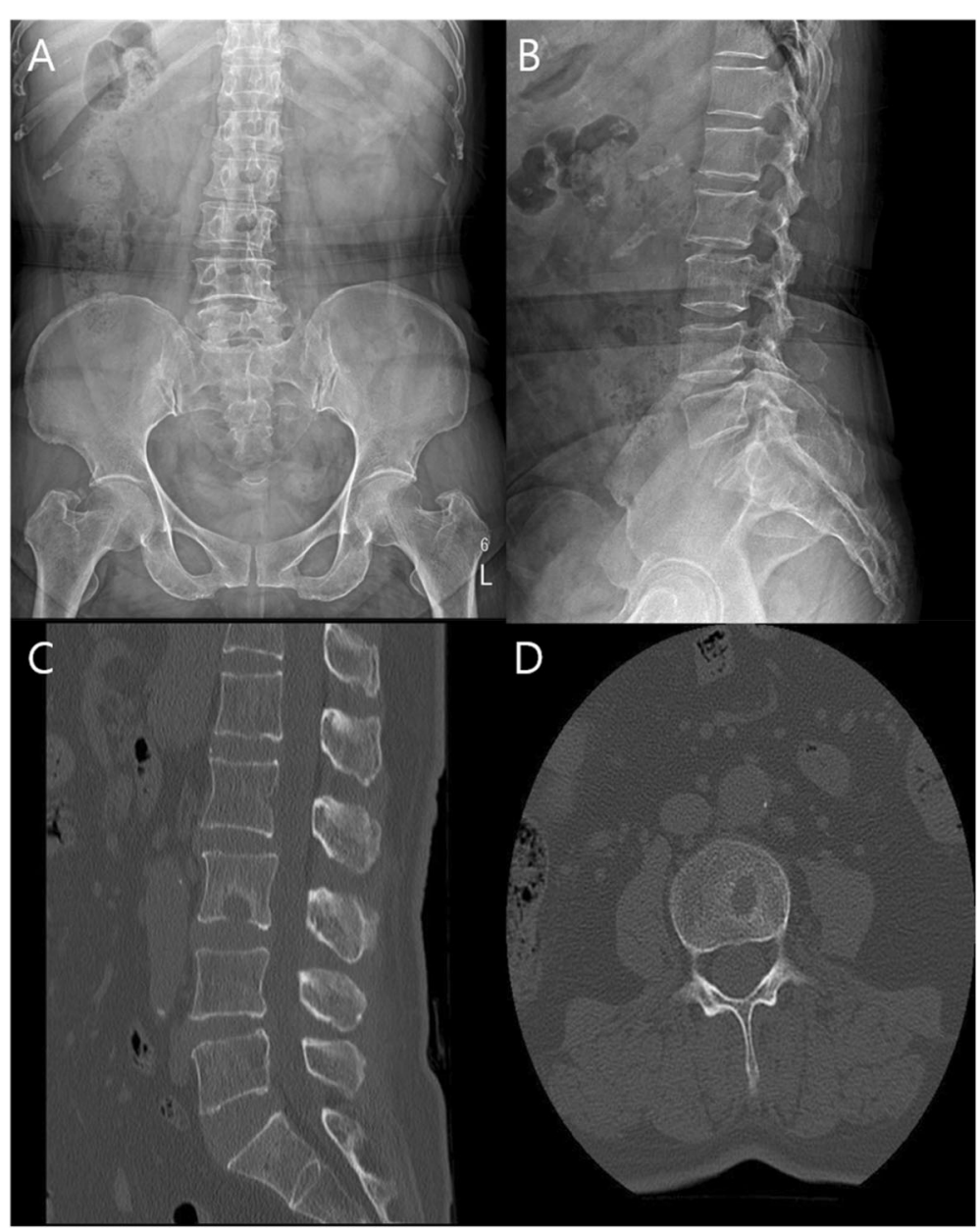

Fig. 1 plain radiograph AP (a) and lateral view (b) showing mild degenerative scoliosis CT scan saggital (c) and axial (d) section showing schmorls node at inferior end plate of $L 3$ vertebra with end plate defect

magnetic resonance imaging (MRI) showed significant increase in size of lesion with focal signal changes in L3-4 disc and marrow changes in anterio-superior part of L4 vertebral body. A computed tomography (CT) at the same time also revealed increase in size of osteolytic lesion in L3 body (Fig. 3). Blood investigations revealed increase in the inflammatory markers suggestive of underlying infective or inflammatory pathology.

\section{Treatment}

We performed partial corpectomy L3 and expandable cage insertion through lateral retroperitoneal approach with posterior bone cement augmented percutaneous pedicle screw fixation L2-L4. Sample sent for histopathological examination and microbiology culture. Post operative MRI showed complete excision of lesion with persistent marrow signal changes at anterio-superior part of L4 vertebral body (Fig. 4). Histopathological report of tissue revealed acute granulomatous inflammation supporting diagnosis of pyogenic vertebral osteomyelitis; however, no organism was grown on microbiological culture. Sample also examined for the Acid fast bacillus, found negative. Empirical intravenous antibiotics (3rd generation cephalosporins + aminoglycosides) started from 1st post operative day and continued for 6 weeks. Patient was comfortable in post operative period with visual analogue scale score 3 at the time of discharge and improved during follow up visits. Inflammatory markers value also significantly reduced.

\section{Discussion and conclusion}

Most of the SNs are asymptomatic and incidental finding [7]. It is reported to occur in 38 to $75 \%$ of population $[4,8]$. it is predominantly found among males of European and American population [9]. The most common anatomical site of SNs to occur is thoracolumbar junction(T7-L1). It most commonly occurs in the superior end plate of lumbar vertebra and inferior end plate of thoracic vertebra [9-11]. 


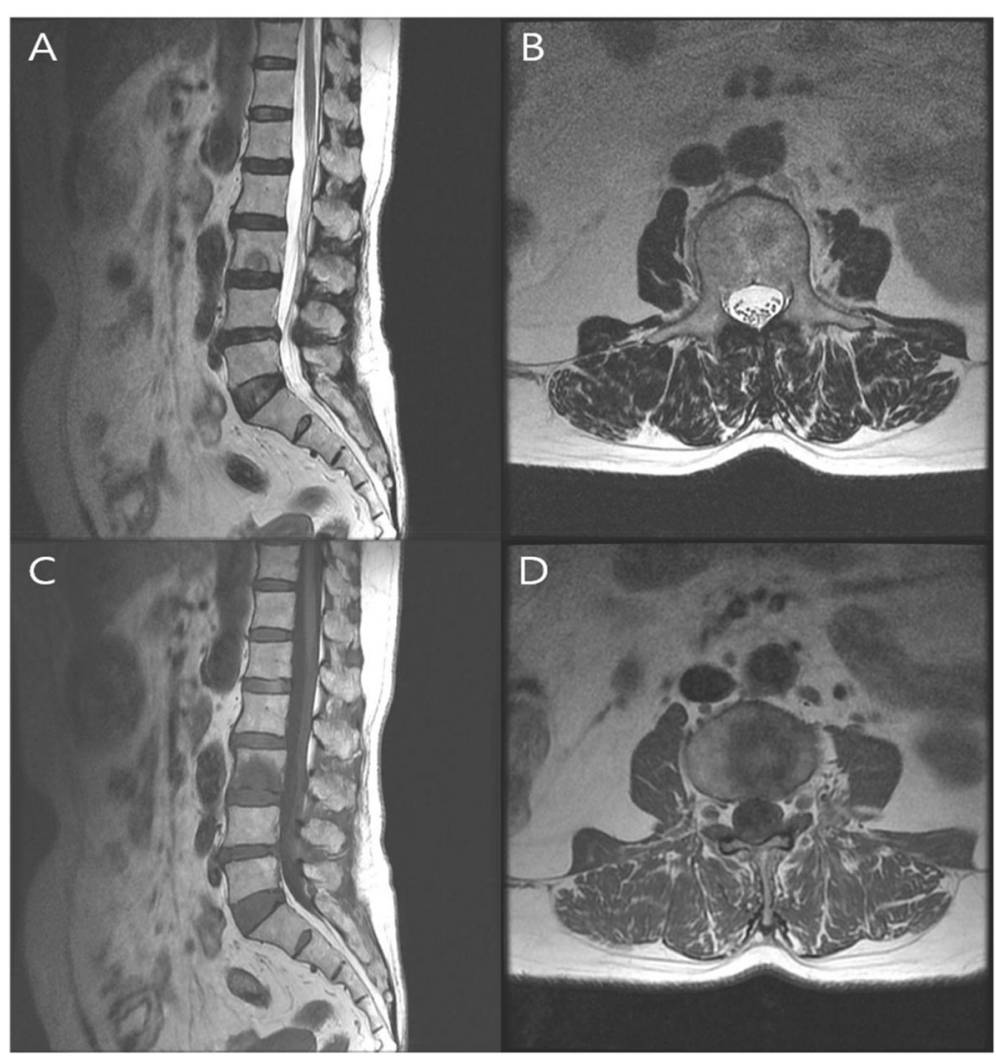

Fig. 2 Initial MRI (a) T2 weighted sagittal image and (b) T2 weighted axial view showings Schmorl's node with iso to high signal intensity, (c) T1 weighted sagittal image and (d) T1 weighted axial image showing low signal intensity

Various theories have been proposed to explain the pathogenesis of $\mathrm{SN}$ in which widely accepted theory is axial load model proposed by Dar et al. [9] They proposed combination of increased range of movement, anteriorly located instantaneous axis of rotation and low disc thickness relative to vertebral body height in thoracic spine makes this region more vulnerable for stress and microfractures which accumulates over period of time to develop into SNs. Zhang et al. [6] postulated the immune system theory for the development of symptomatic SN proposed role of immune reaction to "non self" nucleus pulposus tissue which leads to influx of cytokines, inflammation in vertebral body and pain supported by an MRI study by Takahashi et al. [12] In our case, it is unclear if it developed secondary to weakening of the end plate from infection versus pre-existing SN acting as nidus for infectious bacteria to grow. Only after rapid progression of symptoms; more classical radiological features of spondylitis appeared.

Conventional radiograph has very limited value for diagnosing SNs. It is useful only in late stage of SN where sclerosis appear around lesion. These findings can be seen early and in more details on CT scan. Alternatively, Presence of bone oedema on Dual energy CT can suspect the infective/inflammatory pathology [13]. MRI is gold standard investigation for diagnosing SNs. it also differentiates between symptomatic and asymptomatic $\mathrm{SN}$. symptomatic SNs show low signal intensity on T1 weighted image and high signal intensity on T2 weighted and short tau inversion recovery (STIR) images [12, 14, 15 ] as seen in our report; however, it is difficult to differentiate between benign degenerative bone disease and malignant infiltration or infection in early stages. Gadolinium contrast enhanced MRI can additionally differentiate between the bone oedema or soft tissue swelling from epidural abscess; however, it is contra indicated in patients with allergy to contrast and poor renal function. In the patients with poor renal fuction, diffusion weighted imaging (DWI) may be useful tool to differentiate between infective pathology from non infective cystic lesions. In late stages, MRI shows extensive marrow edema extending more than 2 adjacent vertebral body or structural collapse of vertebral body with paraspinal soft tissue shadows. Tubercular spondylodiscitis can be differentiated from bacterial spondylodiscitis by its rapid progression and sparing of disc space in early stage [16]. In our case, the $\mathrm{SN}$ seemed to be the site of infection because it was a singular lesion with the oedema centred around it, with worsening of oedema on subsequent imaging. 


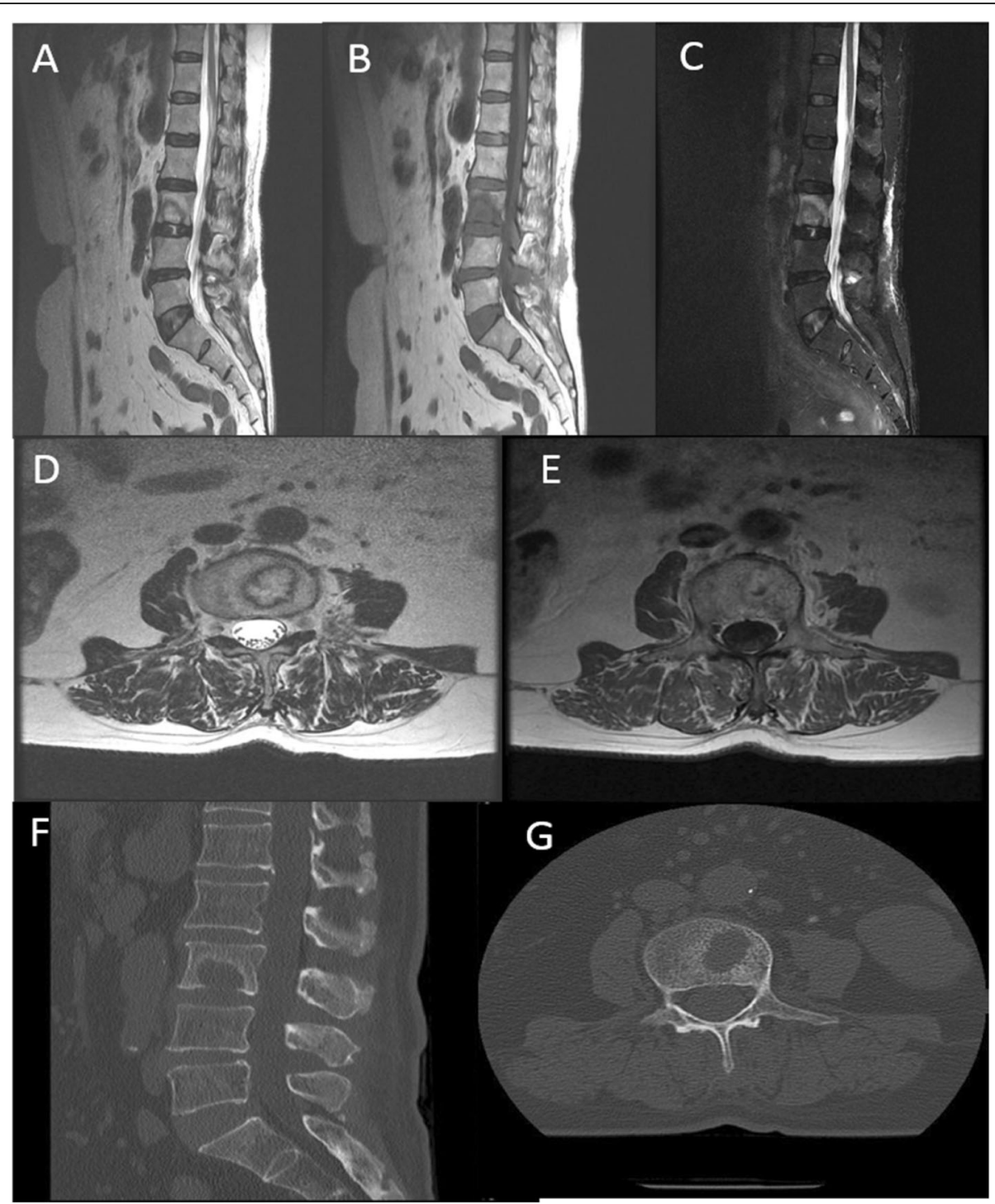

Fig. 3 Repeat MRI (a, b) T1 weighted sagittal image and (c) STIR image showing increased signal intensity in L3 vertebra with anterio-superior part of L4. b Follow-up T2 weighted images showing decreased signal intensity suggestive of extensive marrow oedema. Repeat CT scan saggital (f) and axial (g) section showing increase in size of osteolytic lesion

Conservative line of management always will be first line of management in symptomatic SN. Symptoms usually resolves within 2 to 6 months; however marrow edema on MRI gradually subsides over period of 3 to 12 months [17]. We also initially managed patients with analgesics and bed rest for 4 weeks; despite of which patients pain persisted. There are few case reports of symptomatic SN not responding to medical treatment are managed with surgical treatment. Various less invasive surgical modalities tried for treatment for symptomatic SNs which includes percutaneous vertebroplasty [18], tumor necrosis factor-alpha (TNF-alpha) [19], Rami communicans nerve block [20] successfully.
Peng et al. [21] did segmental fusion surgery (ALIF and PLIF) for severe low back pain not responding to conservative treatment due to $\mathrm{SNs}$ with overall fusion rate of 91\%. Hasegawa et al. [22] performed retroperitoneal excision of an L3 vertebral body for SN. According to him patient improved significantly in post operative period. In our patient we performed excision of lesion with partial corpectomy and expandable cage insertion through lateral retroperitoneal approach.

Typical Histopathological examination of pyogenic vertebral osteomyelitis shows inflammatory cell infiltration, vascular proliferations with granulation tissue, fibrosis, thrombosed blood vessels and bony necrosis depending upon stage of disease; as seen in current case 


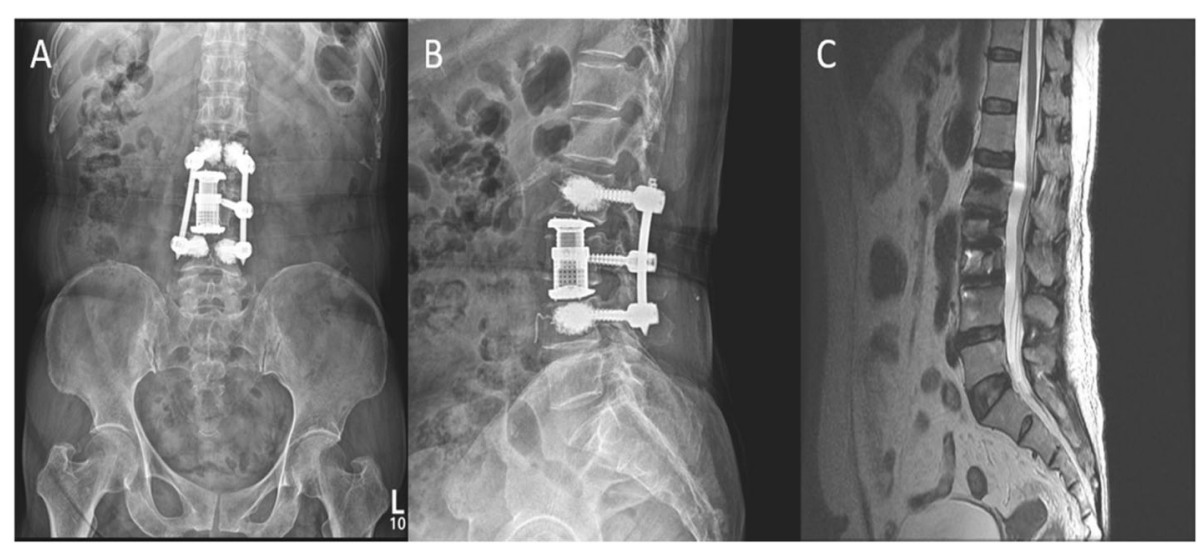

Fig. 4 Post-operative 6 months radiograph: a AP view, b Lateral view, c 6 months follow-up MRI showing complete excision of lesion and complete resolution of osteolytic signal

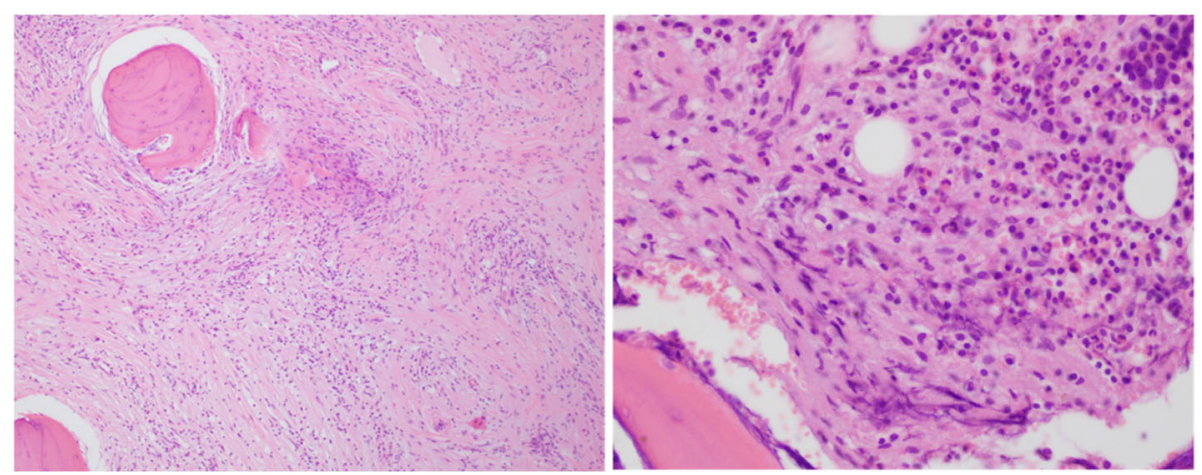

Fig. 5 Histopathology slide (a) $100 \mathrm{HPF}$ and (b) $400 \mathrm{HPF}$ showing inflammatory cells infiltration with acute granulation tissue suggestive of pyogenic vertebral osteomyelitis 
report (Fig. 5). It was not always possible to isolate bacteria from microbiological culture. Depending on clinic radiological findings diagnosis of acute infective $\mathrm{SN}$ with vertebral osteomyelitis is made. Patient started on IV antibiotics for 6 weeks. Patient responded well to treatment with significant pain relief. Many case reports have been found in literature regarding degenerative symptomatic SNs; However, we could not find any reference related to acute infected $\mathrm{SN}$ in the literature. One case reported of tuberculous spondylitis which created diagnostic dilemma with acute symptomatic SN which eventually treated with anti-tubercular drugs [23].

In this study, we present the first report of infectious $\mathrm{SN}$, which is very similar to acute non-infected Symptomatic $\mathrm{SN}$ at the beginning. Therefore, if infected $\mathrm{SN}$ is suspected based on laboratory studies Careful follow-up observation is essential. However, the clinical course along with MRI and CT findings and histological images are more suggestive of infective pathology instead of degeneration hence managed aggressively with excision of infective focus.

$\mathrm{SN}$ is always considered as one of the differential diagnosis of acute low back pain. Most of the time patient responds well to conservative treatment with analgesics and bed rest. Rapid deterioration of symptoms or persistent severe pain despite of conservative treatment should give suspicion of underlying another secondary pathology. It should be aggressively investigated and treated without further delay. MRI is investigation of choice for early diagnosis as well as to differentiate between symptomatic and asymptomatic SN. Currently there is no established treatment modality. Future investigations should address interventions for treating symptomatic SNs.

\section{Abbreviations}

SN: Schmorl's node; MRI: Magnetic resonance imaging; CT: Computed tomography; ALIF: Anterior lumbar interbody fusion; PLIF: Posterior lumbar interbody fusion

\section{Acknowledgments}

We would like to acknowledge scientific team members Ms. Jae Eun Park and Mr. Kyeong Rae Kim for providing assistance in acquiring full text articles and managing digital works.

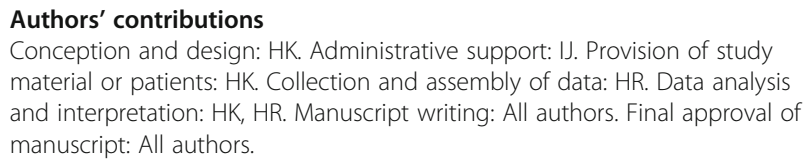
material or patients: HK. Collection and assembly of data: HR. Data analysis and interpretation: HK, HR. Manuscript writing: All authors. Final approval of manuscript: All authors.

\section{Funding}

No funding was obtained for this study.

\section{Availability of data and materials}

The datasets used and/or analysed during the current study are available from the corresponding author on reasonable request.
Ethics approval and consent to participate

Institutional review board of Nanoori hospital has approved present case study.

\section{Consent for publication}

The patient and next of kin has given informed written consent for the submission of a case report to the journal. Present case report complies with the CARE statement.

\section{Competing interests}

The authors declare that they have no competing interests.

Received: 5 December 2019 Accepted: 7 April 2020

Published online: 02 May 2020

\section{References}

1. Leibner ED, Floman Y. Tunneling Schmorl's nodes. Skeletal Radiol. 1998;27: 225-7.

2. Paterakis KN, Brotis AG, Dardiotis E, Hadjigeorgiou GM, Karachalios T, Fountas KN, et al. Acute Schmorl's node during strenuous Monofin swimming: a case report and review of the literature. Glob Spine J. 2012;2: 159-68.

3. Coventry M, Ghormley R, Kernohan J. The intervertebral disc: its microscopic anatomy and pathology: part I. Anatomy, Development, and Physiology. JBJS. 1945:27:105-12.

4. Hilton RC, Ball J, Benn RT. Vertebral end plate lesions (Schmorl's nodes) in the dorsolumbar spine. Ann Rheum Dis. 1976;35:127-32.

5. Fahey V, Opeskin K, Silberstein M, Anderson R, Briggs C. The pathogenesis of Schmorl's nodes in relation to acute trauma: An autopsy study. Spine (Phila Pa 1976). 1998;23:2272-5.

6. Zhang N, Li FC, Huang YJ, Teng C, Chen WS. Possible key role of immune system in Schmorl's nodes. Med Hypotheses. 2010;74:552-4.

7. Jensen MC, Brant-Zawadzki MN, Obuchowski N, Modic MT, Malkasian D, Ross JS. Magnetic resonance imaging of the lumbar spine in people without back pain. N Engl J Med. 1994;331:69-73.

8. Resnick D, Niwayama G. Intravertebral disk herniations: cartilaginous (Schmorl's) nodes. Radiology. 1978;126:57-65.

9. Dar G, Peleg S, Masharawi Y, Steinberg N, May H, Hershkovitz I. Demographical aspects of Schmorl nodes: A skeletal study. Spine (Phila Pa 1976). 2009:34:E312-5.

10. Mok FPS, Samartzis D, Karppinen J, Luk KDK, Fong DYT, Cheung KMC. ISSLS prize winner: Prevalence, determinants, and association of schmorl nodes of the lumbar spine with disc degeneration: A population-based study of 2449 individuals. Spine (Phila Pa 1976). 2010;35:1944-52.

11. Wu HTH, Morrison WB, Schweitzer ME. Edematous Schmorl's nodes on thoracolumbar MR imaging: characteristic patterns and changes over time. Skelet Radiol. 2006:35:212-9.

12. Takahashi K, Miyazaki T, Ohnari H, Takino T, Tomita K. Schmorl's nodes and low-back pain - analysis of magnetic resonance imaging findings in symptomatic and asymptomatic individuals. Eur Spine J. 1995;4:56-9.

13. Nicolaou S, Liang T, Murphy DT, Korzan JR, Ouellette H, Munk P. Dualenergy $C T$ : a promising new technique for assessment of the musculoskeletal system. AJR Am J Roentgenol. 2012;199:S78-86.

14. Stäbler A, Bellan M, Gärtner C, Brossmann J, Reiser MF. MR imaging of enhancing intraosseous disk herniation (Schmorl's nodes). Am J Roentgenol. 1997;168:933-8.

15. Walters G, Coumas JM, Akins CM, Ragland RL. Magnetic resonance imaging of acute symptomatic schmorl's node formation. Pediatr Emerg Care. 1991: 7:294-6.

16. Kumar Y, Gupta N, Chhabra A, Fukuda T, Soni N, Hayashi D. Magnetic resonance imaging of bacterial and tuberculous spondylodiscitis with associated complications and non-infectious spinal pathology mimicking infections: a pictorial review. BMC Musculoskelet Disord. 2017;18:244.

17. Grivé E, Rovira A, Capellades J, Rivas A, Pedraza S. Radiologic findings in two cases of acute Schmorl's nodes. Am J Neuroradiol. 1999:20:1717-21.

18. Wenger $M$, Markwalder TM. Fluoronavigation-assisted, lumbar vertebroplasty for a painful Schmorl node. J Clin Neurosci. 2009:16:1250-1.

19. Sakellariou GT, Chatzigiannis I, Tsitouridis I. Infliximab infusions for persistent back pain in two patients with Schmorl's nodes. Rheumatology. 2005:44: 1588-a. 
20. Jang JS, Kwon HK, Lee JJ, Hwang SM, Lim SY. Rami Communicans Nerve Block for the Treatment of Symptomatic Schmorl's Nodes -A Case Report. Korean J Pain. 2010;23:262.

21. Peng B, Chen J, Kuang Z, Li D, Pang X, Zhang X. Diagnosis and surgical treatment of back pain originating from endplate. Eur Spine J. 2009;18: 1035-40.

22. Hasegawa K, Ogose A, Morita T, Hirata Y. Painful Schmorl's node treated by lumbar interbody fusion. Spinal Cord. 2004;42:124-8.

23. Pandita A, Madhuripan N, Hurtado RM, Dhamoon A. Back pain and oedematous Schmorl node: a diagnostic dilemma. BMJ Case Rep. 2017; 2017:bcr2017.

\section{Publisher's Note}

Springer Nature remains neutral with regard to jurisdictional claims in published maps and institutional affiliations.

Ready to submit your research? Choose BMC and benefit from:

- fast, convenient online submission

- thorough peer review by experienced researchers in your field

- rapid publication on acceptance

- support for research data, including large and complex data types

- gold Open Access which fosters wider collaboration and increased citations

- maximum visibility for your research: over $100 \mathrm{M}$ website views per year

At BMC, research is always in progress.

Learn more biomedcentral.com/submissions 